\title{
L2 universidad:
}

\section{entre la responsabilidad social y el individualismo ${ }^{(*)}$}

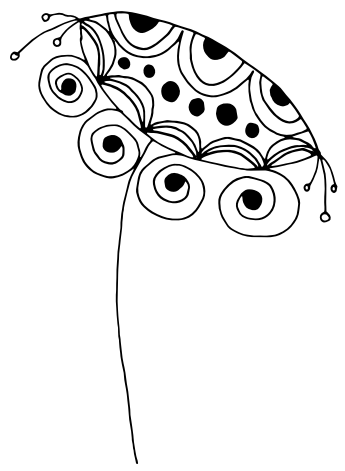

\section{La universidad}

Sin ser el objetivo central de nuestras reflexiones el día de hoy, conviene recordar que la universidad es una de las más antiguas instituciones existentes; acompaña a Occidente y al mundo desde fines del siglo XII hasta la actualidad, no solo confiriendo los instrumentos fundamentales para la creación y la difusión del saber en un plano científico o académico sino, también, penetrando profundamente en las estructuras económicas, políticas, sociales y mentales. Nació espontáneamente, como consecuencia del afán de adquirir conocimientos entre algunas personas que volvían la mirada a los antiguos textos para encontrar una explicación del mundo que los rodeaba. Era una comunidad de estudiantes y maestros que se reunía en una ciudad para intercambiar información y conocimientos, con plena libertad y autonomía, de tal manera que, después de un proceso de formación académica,brindaba una licencia para enseñar, lo que mucho tiempo después se convertiría en la obtención de una licencia para ejercer una profesión.

De esta manera, se produjo el tránsito del antiguo intelectual errante, observador acucioso e itinerante de la realidad, al universitario, estudiante sedentario y alimentado por un creciente flujo de información que le permitía ampliar las fronteras de su conocimiento. La

\footnotetext{
Discurso pronunciado el 9 de septiembre de 2013, con ocasión de la inauguración del semestre académico 2013-II de la Universidad Ricardo Palma.
}

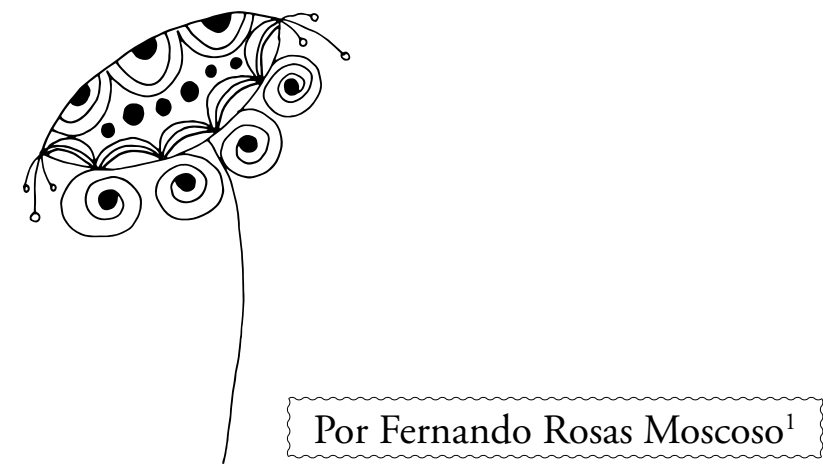

corporación universitaria nació en esos tiempos, como otras tantas, dentro de un proceso de conformación de comunidades de gente animada por un mismo espíritu, con objetivos comunes o vinculada al desarrollo de una misma actividad. Dicho proceso -expresión característica de sus dos siglos iniciales en todo el Occidente europeo- incorporó cada vez un mayor número de seguidores, convirtiendo a la universidad en una expresión internacional que reflejaba los cambios profundos que generaba el proceso de formación del sistema capitalista.

La toma de conciencia corporativa se fue consolidando y evolucionando hacia formas cada vez más complejas, que lentamente condujeron hacia una elitización,que si bien concede a las universidades un mayor poder en relación a los contextos en los que se desenvuelve, la va alejando del sentido de espontaneidad y universalización que inicialmente tuvo. Es por eso que los universitarios del siglo XIV son muy diferente de aquellos que acompañaron los inicios de esta institución. La presencia de la universidad es contradictoria en las sociedades que la albergan. En el plano político fue necesaria para el funcionamiento de los jóvenes del estado-nación que se iba consolidando, pero a la vez generó las principales críticas al poder, que en determinados momentos produjo una inestabilidad preocupante. Es por eso que la autoridad pretendió intervenir sobre ella, aunque sin resultados permanentes y positivos. La tentación por el control de la universidad fue dificultada por una autonomía aceptada desde sus orígenes y alimentada por el poder 


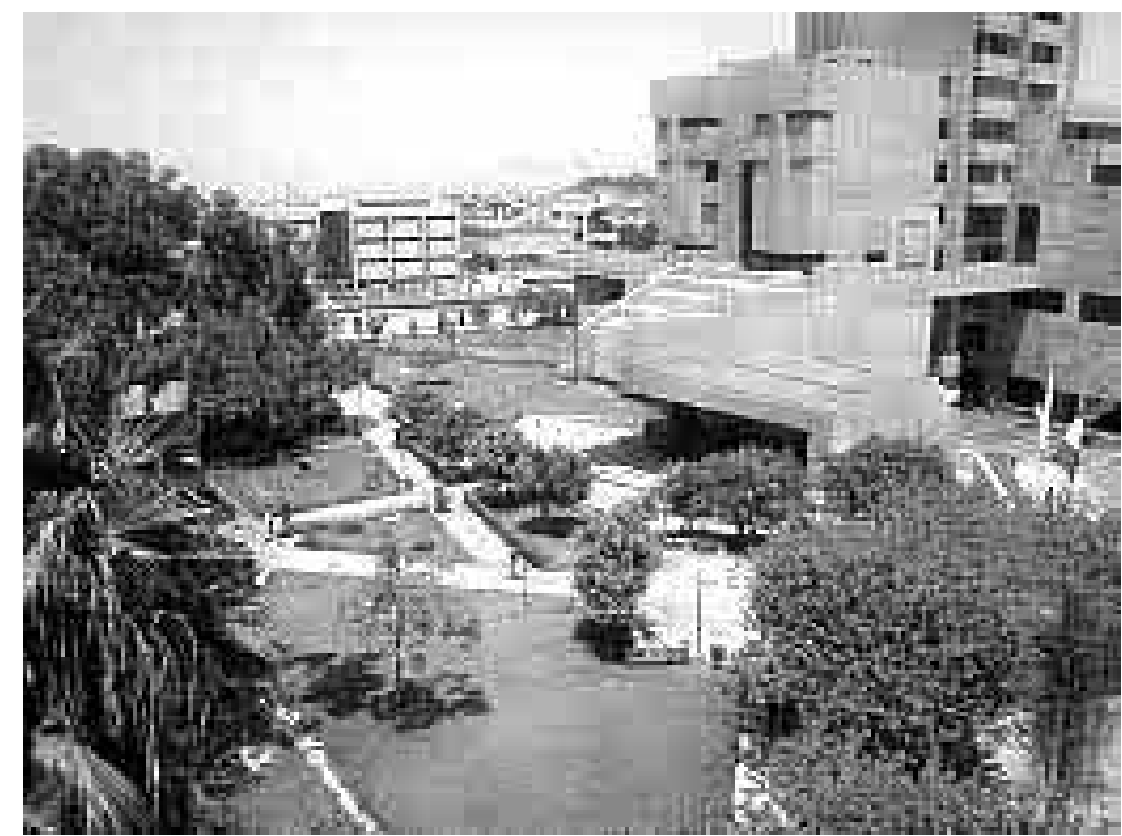

que define el conocimiento y la experiencia. Si bien la Iglesia en esos momentos iniciales tuvo una influencia muy importante sobre ella, no llegó a convertirla total y permanentemente en un instrumento de sus intereses no solo espirituales sino también políticos.

La universidad, institución antigua en permanente transformación, refleja a lo largo de su historia el profundo interés por la creación, la acumulación y la difusión del conocimiento, y también por la transformación que debe acompañar al progreso y al desarrollo humano. Ese permanente compromiso con el cambio y su relación profunda con las características de las diversas sociedades que la albergaban, se reflejan en lo que es una endémica presencia de la crisis en su seno. Todas las etapas que vive la universidad a lo largo de su existencia institucional están moldeadas por la permanente presencia de esa condición, que finalmente no es otra cosa que parte inherente de su propia existencia. En otras palabras, la institución universitaria siempre estuvo y estará en crisis, por la intensa dinámica de los elementos que la constituyen y que forman parte de sus líneas maestras de existencia. La búsqueda del conocimiento, el progresivo compromiso con la realidad que la rodea, la crítica y la vocación por la transformación y el cambio, además de muchos otros factores materiales y espirituales, conducen a esa situación de permanente crisis, así como también a la cambiante situación de los elementos que la rodean. Cada siglo y cada momento se convierten así en desafíos para la institución universitaria, en nuevos retos para el uso de la razón en la interpretación y la transformación de la realidad que la rodea. Todo ello es parte de la esencia misma de la vida universitaria.
Es por eso que actualmente nuevos desafíos llevan a la universidad a replantear viejos esquemas y a generar nuevas respuestas y soluciones.

\section{La responsabilidad social}

Entre los retos nuevos que enfrenta la universidad en la época actual, está presente el concepto de Responsabilidad Social, una preocupación que nace en diversos campos de la actividad pública y privada a fines del siglo XX y que se ha incorporado a la inquietud y al interés de las universidades, llegando a incluirla dentro de su estructura orgánica, y que busca canalizar la acción de la universidad como corporación en proyectos y actividades que impacten positivamente en el conjunto de la sociedad. Aquello que anteriormente se concentraba en la actividad de proyección social universitaria adquirió, hace poco tiempo, un nuevo enfoque en la definición de una responsabilidad concreta de la universidad hacia la sociedad que la alberga, a tono con los parámetros conceptuales del presente.

Es cierto que desde siempre la universidad interactúa intensa y permanentemente con la realidad social que la rodea, y que el concepto de responsabilidad tiene una relación de vieja data, pero es en los últimos tiempos que, alimentada por una toma de conciencia de la responsabilidad social, empieza a adquirir instituciones u organizaciones de muy diversa naturaleza, que obligan a repensar el sentido de esa tarea en su seno.

A manera de ejemplo de esa nueva percepción, podemos transmitir una experiencia a inicios de 


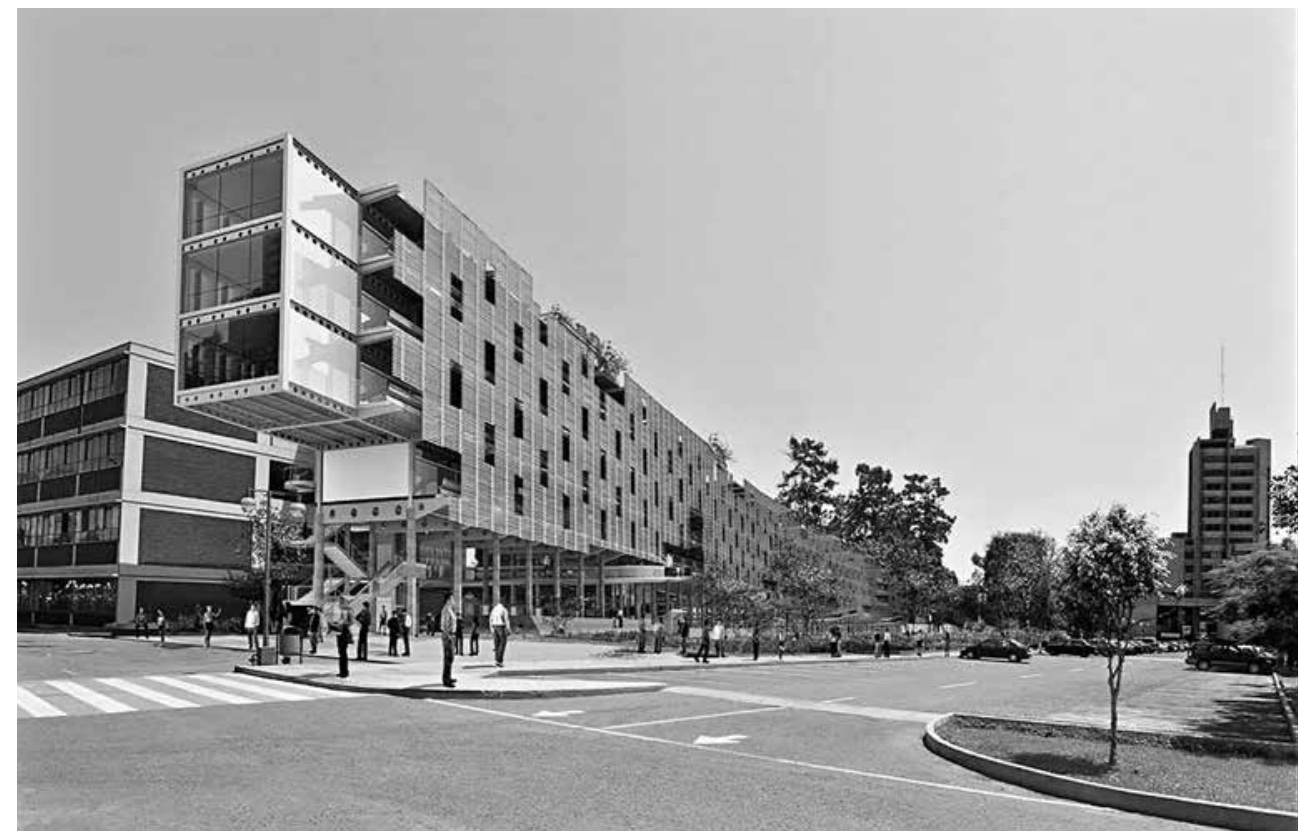

los años noventa, cuando tuve la oportunidad de preparar, junto a autoridades de la antigua Universidad de Lovaina, un proyecto de convenio de apoyo integral para una nueva facultad en la universidad en la que laboraba en esa época. Concentramos nuestra atención en todos los aspectos académicos posibles, adecuándonos a los objetivos de una universidad tan antigua e importante como la de Lovaina, Bélgica; sin embargo,cuando elevamos conjuntamente el proyecto ante las autoridades belgas correspondientes, la observación más importante que nos hicieron estuvo referida a la responsabilidad social que tenía que asumir la nueva unidad académica y que no se explicitaba claramente en el proyecto; así, se tuvo que organizar todo un rubro sobre el trabajo social de nuestros estudiantes en contextos económicamente deprimidos, pero a la vez, perfectamente integrado a la formación profesional a la que se pretendía llegar: excelencia académica y compromiso concreto con la realidad social en un país como el nuestro. Subsanado ese aspecto, el proyecto se concretó y a lo largo de varios años dichos estudiantes no solamente recibieron los beneficios de una alianza estratégica con una antigua e importante universidad, sino también aportaron a la mejor calidad de vida de los conciudadanos.

Existe una enorme cantidad de rutas de acción dentro de esta nueva perspectiva de la Responsabilidad Social; los campos son diversos, los escenarios en los que el universitario y el profesional pueden actuar son innumerables; nuestro país es un inmenso laboratorio, donde cada una de las carreras profesionales puede concretar positivas acciones de transformación y mejora para nuestra sociedad. Sin negar la trascendencia de este tipo de política universitaria, que se consolida cada vez más en nuestras instituciones, sentimos que no debemos perder de vista lo que consideramos la principal responsabilidad social de la universidad: ofrecer a la sociedad los profesionales más competentes y calificados.

Siendo ello uno de los dos objetivos de nuestras reflexiones el día de hoy, debemos enfatizar que esa responsabilidad social de la universidad tiene como pilar fundamental la cada vez mayor exigencia académica, porque formar profesionales competentes es exigir de todos y cada uno de nuestros estudiantes la mejor calificación posible. En ese sentido, y quizás influidos por las nuevas características de la competencia actual entre universidades y, ahora último, por la existencia de universidades con fines de lucro, se ha caído en el error de avalar políticas generosas e irresponsables en la calificación y evaluación académica de los estudiantes. Se siente cada vez más preocupación por la pérdida de estudiantes debido a la desaprobación o que el presupuesto de la universidad es más importante que los objetivos académicos, llevando todo ello a una flexibilización en los esquemas de evaluación, que finalmente hacen perder de vista la principal responsabilidad social de la universidad y también los objetivos fundamentales que la animan desde sus orígenes.

Es indudable que la desaprobación y el retraso en los estudios genera malestar, pero también se debe entender que el objetivo fundamental es la formación de buenos 
profesionales y no simplemente el otorgamiento generoso y fácil de títulos universitarios que después van a traer consigo graves resultados para la sociedad en su conjunto. Es fácil imaginar cómo puede afectar la mala formación de un médico o un ingeniero, que puede ocasionar pérdidas irreparables o cuantiosas en su entorno, pero ese peligro no desaparece en todas las demás carreras universitarias, porque cada uno de los profesionales debe tener un conocimiento y una experiencia que los proteja del error y la acción irresponsable.

Actualmente, dentro de una sociedad de consumo, en donde diversas fuerzas presionan sobre el individuo para obtener en el menor tiempo posible la capacidad de generar bienes y de alcanzar el éxito, la conciencia de ser profesional en lo que a la responsabilidad se refiere, se va diluyendo y convirtiendo en parámetros gaseosos o aspectos secundarios en relación a los objetivos de la vida actual. Es por ello que la búsqueda del desarrollo humano, en su sentido más profundo, se aleja de las inquietudes fundamentales del individuo que ingresa al escenario del quehacer profesional. Todo ello también toca el tema de los valores, pues al no estar comprometidos con ese desarrollo colectivo y profundamente humano, se genera una defectuosa formación ética y ciudadana.Las universidades forman a las personas y en esencia su formación es profundamente humanística; en ese sentido, los parámetros o tendencias de una sociedad de consumo no deben alterar sus objetivos fundamentales.

\section{El individualismo}

Uno de los aspectos de la vida del hombre en sociedad es el individualismo, que alcanza actualmente enorme importancia al ser expresión del sistema capitalista que nos envuelve y que contribuye a exaltarlo, en base a los principios del Liberalismo que nació a fines del siglo XVII. Conviene recordar que si bien es un tema presente desde los orígenes de la cultura occidental, es con el Humanismo, que brota en los siglos XV y XVI, cuando adquiere una mayor dimensión teórica y práctica.

El individualismo humanista es un auténtico signo de cambio y renovación, y se alimenta de la idea central que consideraba al hombre como centro y medida de todas las cosas. El abandonar una concepción universalista, enmarcada en la trascendencia religiosa, significó la recuperación de lo uno frente al todo, de la autonomía individual y de la potencialidad del hombre frente a su destino, aun cuando inicialmente no rompiera con su fe. Ese individualismo humanista y renovador fue desarrollándose a lo largo de los últimos siglos, llegando actualmente a asumir un rol fundamental aunque perturbador en la vida de la gente. En ese sentido, se observa que en el presente se va forjando la idea de un individualismo potencialmente peligroso al generar un abandono de las perspectivas comunitarias, es decir, de la construcción de una sociedad justa e igualitaria.

Hoy se habla mucho acerca de un capitalismo de consumo y hedonístico, que contrasta con las expresiones comunitarias que surgieron desde fines del siglo XIX, que recibieron la influencia de la relación fisiológica entre democracia y autonomía individual, base del pensamiento liberal inglés del siglo XVIII y de la filosofía francesa de "las luces". Muchos intelectuales se ocupan del estudio del individualismo contemporáneo

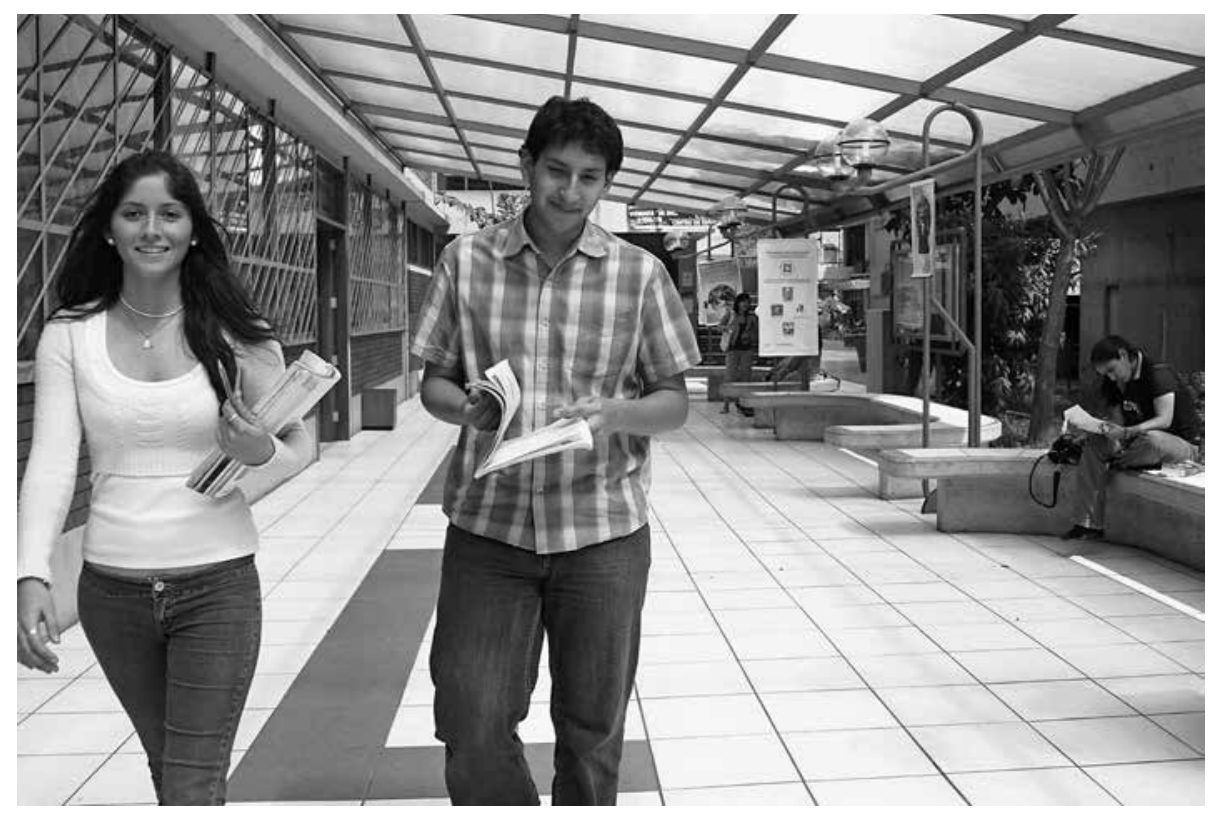


y del abandono de los llamados compromisos colectivos ante un individualismo exacerbado por el capitalismo de consumo.

En su reciente visita a Lima, Gilles Lipovetsky resaltó que no hay que tener una mirada apocalíptica del individualismo actual, ya que involucra un modo personal de llegar a los compromisos colectivos. Las exigencias de hoy en términos de competencia, imagen, materialismo y exaltación de la autoestima, generan una cierta desorientación entre los individuos, cuyo entorno no favorece la percepción clara de su papel en el interior de la sociedad. La búsqueda de objetivos pragmáticos, reflejados en el éxito individual y en la posesión de bienes y conocimientos, rompe con la integración y el sentido de pertenencia al grupo.

Esta situación se refleja en la universidad, que es el escenario todavía considerado como trampolín indispensable en términos de éxito personal y social, pero a la vez obstáculo o prueba de fuego para el logro de los fines que la sociedad misma alimenta en esa visión exagerada del triunfo de lo individual. Así, la universidad puede alimentar la inseguridad, la baja autoestima, la incertidumbre vocacional, la descontextualización social, y resaltar las carencias y problemas personales, como también las herencias que la sociedad en su conjunto refleja en cada individuo, tanto en lo negativo como en lo positivo. En ese sentido, desde el ingreso a la universidad y al asumir progresivamente todos los pasos que en su interior se tienen que recorrer, tanto desde el punto de vista académico como en lo social, económico y político, se generan tensiones que los jóvenes individuos van a asumir con éxito o fracaso, pero siempre dentro de una idealización de lo práctico y de una exigencia de supuestos derechos, en donde se olvidan los compromisos sociales que deben asumir.

A pesar de todo, es posible lograr un modo personal de compromiso social que quizás no se enmarque, como tiempo atrás, en compromisos ideológicos y corporativos, sino más bien en una relación individual y directa que parte de una sensibilidad todavía latente dentro de esa construcción humanística que viene desde los siglos XV y XVI. Ese Humanismo que surgió como praxis y ciencia no ha desaparecido, tiene la capacidad de transformarse al paso de los tiempos, pero bajo el estímulo de instituciones o quehaceres como los que expresa la vida universitaria. La definición del nuevo humanismo del presente es responsabilidad de la universidad, que no busca simplemente otorgar licencias para construir, o medicar, sino que busca formar a las personas en la ética, en los valores y en la sensibilidad frente al conocimiento, la cultura y la técnica.

La tarea que la universidad del presente enfrenta es difícil en un contexto donde la idealización de lo práctico y el logro del bienestar material son los objetivos fundamentales. Pocas instituciones tienen tal responsabilidad y la universidad no puede abandonar su papel trascendente en la búsqueda del pleno desarrollo humano; todos y cada uno de los aspectos que define su actividad cotidiana deben estar enmarcados en ese objetivo final, que al separarse del individuo que pasó por ella deje una huella profunda en él al fomentar su responsabilidad social dentro de las múltiples formas de construirla. De esa manera, la principal Responsabilidad Social de la Universidad

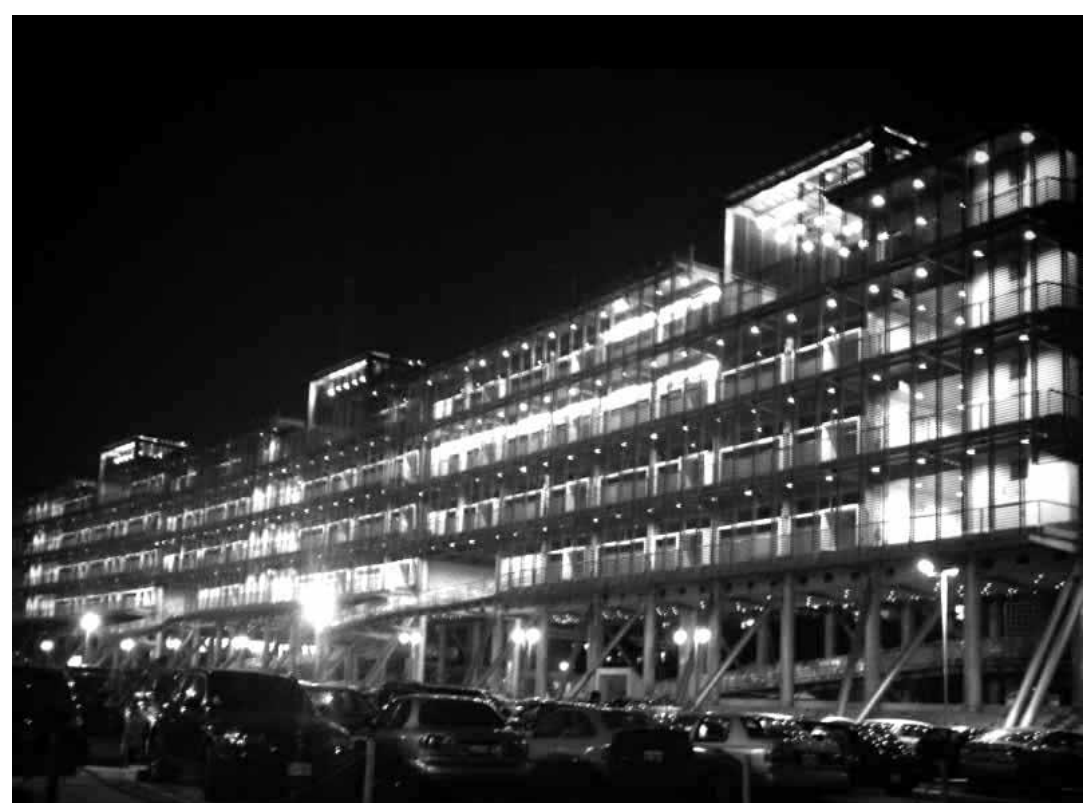


entra en armónica relación con el individualismo profundamente humanista que debe sustentar la vida humana a través de los tiempos.En ese sentido, supuestos obstáculos como la exigencia académica o el permanente respeto a la ética y los valores constituyen parte inherente de su sentido profundo de creación, renovación y transmisión del conocimiento.

\section{Nuestra universidad}

La Universidad Ricardo Palma es una institución universitaria de viejo cuño, de larga y fructífera historia y que mantiene los valores tradicionales de las universidades iniciales; no es una universidad que se transforma al compás de los nuevos ídolos del presente, no modifica sus objetivos ni sus instrumentos de trabajo en la búsqueda de un bienestar material animado por el lucro o la tentación que él ejerce en nuestro tiempo. Es una universidad que se funda en tres pilares, a mi juicio, fundamentales para cualquier institución universitaria: humanismo, tradición y modernidad.

El humanismo es el flujo vital permanente de la vida universitaria, la sangre que alimenta a cada uno de sus componentes y que la proyecta en una acción transformadora y revitalizadora de la sociedad en su conjunto. Un humanismo que forma no solamente profesionales, sino también buenas personas, responsables de sí mismas y de sus relaciones con los demás, que implica un crecimiento personal, pero a la vez un crecimiento colectivo y la búsqueda permanente de una sociedad justa e igualitaria. Tradición: desde el sentido correcto del término no implica conservadurismo sino conciencia de sus propias raíces inmersas en un tiempo y en un espacio; raíces sólidas y vitales que permiten su permanencia en el tiempo y su resistencia a las tensiones o incluso a las agresiones de entornos cambiantes y coyunturales; en otras palabras: un sentido claro del origen y del proceso vital transcurrido. Modernidad es un término más adecuado y constante frente a lo fluctuante de otros términos, quizás más estimados el día de hoy, como ciencia o tecnología. La modernidad refleja un sentido del presente, pero con proyección al futuro y con raíces sólidas en el pasado; además, la modernidad asume el carácter profundamente humano de la creación, la transformación y la difusión del conocimiento al paso del tiempo.

Sin rendirse frente a los cantos de sirena que envuelven la vida de las universidades en nuestro contexto, la Universidad Ricardo Palma persiste en los ideales originales, pero a la vez está profundamente comprometida con la sociedad que la cobija y con la responsabilidad social que la anima, dentro del contexto de un nuevo individualismo también creador y positivo.

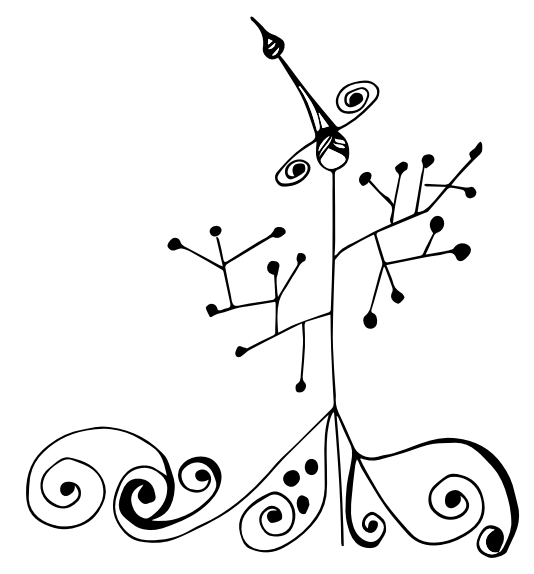

